\title{
The depot-specific and essential roles of CBP/p300 in regulating adipose plasticity
}

\author{
Maria Namwanje 1,*, Longhua Liu1,*, Michelle Chan², Nikki Aaron1,3, Michael J Kraakman and Li Qiang1 \\ ${ }^{1}$ Naomi Berrie Diabetes Center, Department of Pathology and Cell Biology, Vagelos College of Physicians and Surgeons, Columbia University, New York, \\ New York, USA \\ 2Department of Biological Sciences, Columbia University, New York, New York, USA \\ 3Department of Pharmacology, Vagelos College of Physicians and Surgeons, Columbia University, New York, New York, USA \\ ${ }^{4}$ Naomi Berrie Diabetes Center, Department of Medicine, Vagelos College of Physicians and Surgeons, Columbia University, New York, New York, USA
}

Correspondence should be addressed to L Qiang: Iq2123@cumc.columbia.edu

*(M Namwanje and L Liu contributed equally to this work)

\begin{abstract}
Fat remodeling has been extensively explored through protein deacetylation, but not yet acetylation, as a viable therapeutic approach in the management of obesity and related metabolic disorders. Here, we investigated the functions of key acetyltransferases $\mathrm{CBP} /$ p300 in adipose remodeling and their physiological effects by generating adiposespecific deletion of CBP (Cbp-AKO), p300 (p300-AKO) and double-knockout (Cbp/p300-AKO) models. We demonstrated that $C b p-A K O$ exhibited marked brown remodeling of inguinal WAT (iWAT) but not epididymal WAT (eWAT) after cold exposure and that this pattern was exaggerated in diet-induced obesity (DIO). Despite this striking browning phenotype, loss of Cbp was insufficient to impact body weight or glucose tolerance. In contrast, ablation of $p 300$ in adipose tissues had minimal effects on fat remodeling and adiposity. Surprisingly, double-knockout mice (Cbp/p300-AKO) developed severe lipodystrophy along with marked hepatic steatosis, hyperglycemia and hyperlipidemia. Furthermore, we demonstrated that pharmacological inhibition of $\mathrm{Cbp}$ and p300 activity suppressed adipogenesis. Collectively, these data suggest that (i) CBP, but not p300, has distinct functions in regulating fat remodeling and that this occurs in a depot-selective manner; (ii) brown remodeling occurs independently of the improvements in glucose metabolism and obesity and (iii) the combined roles of CBP and p300 are indispensable for normal adipose development.
\end{abstract}

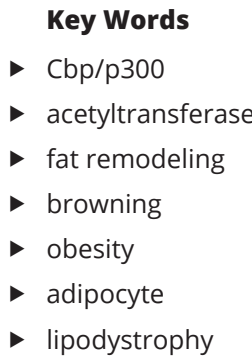

Journal of Endocrinology (2019) 240, 257-269

\section{Introduction}

White adipose tissue (WAT) is characterized by unilocular lipid-filled adipocytes, low Ucp1 expression and a primary function of energy storage, while brown adipose tissue (BAT) is characterized by multilocular lipid droplets within its adipocytes, high Ucp1 expression and a high capacity for energy expenditure and thermogenesis. Browning of WAT is defined by the presence of brown-like or 'beige' cells interspersed within WAT that result in the switch of
WAT function from energy storage to energy expenditure and is thereby associated with better metabolic outcomes marked by reduced body weight, increased oxygen consumption and improved glucose metabolism (Guerra et al. 1998, Petrovic et al. 2010, Vegiopoulos et al. 2010, Seale et al. 2011, Wu et al. 2012). With the use of genetically modified mouse models, pharmacological agents and environmental cues, we and others have been 
able to identify different factors involved in the regulation of adipose tissue remodeling, which serves as a promising therapeutic tool in the treatment of obesity and its associated comorbidities (Coskun et al. 2008, Bordicchia et al. 2012, Qiang et al. 2012, Zhang et al. 2014).

Sirtuin 1 (SirT1), the NAD+-dependent deacetylase, is known to play significant roles in regulating metabolism, as the overexpression of SirT1 in mice results in improved glucose homeostasis, induction of browning and expression of browning markers in inguinal WAT after cold challenge (Banks et al. 2008, Qiang et al. 2012, Xu et al. 2013). Similarly, pharmacological activation of SirT1 with agents such as Resveratrol and SIRT1720 can protect from obesity, increase energy expenditure and improve insulin sensitivity (Lagouge et al. 2006, Milne et al. 2007, Feige et al. 2008). Conversely, SirT1-knockout mice exhibit increased body weight, insulin resistance and inflammation in epididymal WAT, all as a consequence of DIO (Gillum et al. 2011, Chalkiadaki \& Guarente 2012, Mayoral et al. 2015, $\mathrm{Xu}$ et al. 2016). As such, the phenomenon that increasing deacetylase activity regulates adipose remodeling suggests that the repression of acetyltransferase activity may be an alternative approach toward targeting obesity and its comorbidities.

CBP (CREB-binding protein) and p300 (E1a-binding protein) comprise the KAT3 family, a sub-class of histone acetyltransferases, and the sequence similarity between the two proteins suggests functional likeness (Bedford et al. 2010). They primarily function through their acetyltransferase activity and their interactions with other transcription factors in the regulation of gene transcription (Kasper et al. 2010). CBP and p300 regulate energy homeostasis in major metabolic organs including the liver, skeletal muscle and adipose tissue (Roth et al. 2003, He et al. 2009, Bedford et al. 2011, He et al. 2012, 2013). The importance of CBP in energy homeostasis is suggested by the fact that $C b p$ heterozygous-null mice were protected from DIO and improved glucose metabolism (Yamauchi et al. 2002). Phosphorylation of CBP at serine 436 increased responses to insulin and metformin upon suppression of hepatic gluconeogenesis, whereas mice carrying a phosphorylation-deficient mutation suffered from insulin intolerance (He et al. 2009). Additionally, mutant mice in which the $\mathrm{CH} 1$ domains of the $\mathrm{p} 300$ and Cbp proteins were deleted display reduced body weight and adiposity and improved glucose and insulin tolerance (Bedford et al. 2011). Most recently, the loss of Cbp in the hypothalamus was shown to result in obesity, glucose intolerance and insulin resistance (Moreno et al. 2016). In contrast, mutations in CBP and p300 in humans are often found in a rare genetic congenital disease named Rubinstein-Taybi syndrome, and patients with this disease develop obesity around puberty (Milani et al. 2015). These studies collectively indicate that CBP and p300 play significant roles in energy metabolism; however, their specific roles in regulating adipose tissue function and remodeling are yet to be examined.

In this study, we sought to investigate the direct effects of acetyltransferase on adipose tissue remodeling by selectively inducing the deletion of $\mathrm{Cbp}$ and/or $p 300$ using the adiponectin-Cre recombinase. While the adipose loss of $p 300$ did not have a significant impact on adipose remodeling, the loss of $C b p$ selectively induced browning in inguinal WAT and reduced both adipose tissue mass and adipocyte size. In addition, the double-knockout mice, Cbp/p300-AKO, exhibited severe lipodystrophy accompanied by hyperglycemia, hyperlipidemia and hepatic steatosis. Furthermore, we demonstrated that selective inhibition of Cbp and p300 activity in vitro, using 3T3-L1 cells, suppressed adipogenesis. Our study highlights the unique functions of $\mathrm{CBP}$ and p300 in the regulation of fat remodeling and development and provides evidence for the therapeutic potential of CBPand p300-selective inhibitors in the treatment of obesity.

\section{Materials and methods}

\section{Animal studies}

Cbpflox/flox (Kang-Decker et al. 2004), p300flox/flox (Kasper et al. 2006) and adiponectin-Cre (adipoq-Cre) (Eguchi et al. 2011) mice and the genotyping primers have been previously described. These mice were purchased from Jackson Laboratories. In order to target gene deletion to adipose tissue, we crossed $C b p^{f l o x}$ or $p 300$ flox with adipoqcre mice to generate Cbpflox/flox, adipoq-Cre $(C b p-A K O)$ and $C b p^{F / F}$ (controls); p300flox/flox, adipoq-Cre (p300-AKO) and p300F/F (controls). Different mating combinations were used to generate double mutants with $C b p$ and $p 300$ conditional deletion in adipose tissue (Cbp/p300-AKO). Littermates without Cre recombinase, $C b p^{F / F} / p 300^{F / F}$, were used as controls in the experiments. The deletion of CBP exon 9 (2002-2119) was confirmed by using primer Cbp-F: ACTCTGGTAACATTGGAAGCC and CbpR: AGCCCCAGAAGCTGGTAAAG, while p300 exon 9 (2179-2296) deletion was confirmed by using primer p300-F: CCTTTGCCAACAGCAGCTCA and p300-R: GACCCATGCCAGGAGCATT. Studies in the doubleknockout mice were done at 12 weeks of age. Mice were housed on a 12-h light/darkness cycle with access 
to regular chow (Pico Lab Diet 5053, Purina Mill Inc, Brentwood, MO, USA) and water ad libitum. For chronic cold exposure, 8-week-old mice were housed at $4^{\circ} \mathrm{C}$ for 4 days and their body temperature was measured at the same time daily during the 12-h light cycle. Eight-week-old mice were maintained on a high-fat diet (HFD) consisting of $60 \%$ calories from fat (D12492, Research Diets Inc) for 8-12 weeks to promote DIO. The Institutional Animal Care and Use Committee at Columbia University approved all animal protocols.

\section{Metabolic assessment}

We measured body composition by nuclear MRI (Echo Medical systems, Houston, TX, USA). To assess glucose tolerance, mice were fasted for $16 \mathrm{~h}$ and given access to water ad libitum. We injected mice intraperitoneally (i.p) with $20 \%$ D-glucose at a dose of $1 \mathrm{~g} / \mathrm{kg}$ body weight. For the insulin tolerance test, mice were fasted for $4 \mathrm{~h}$. After measuring the base blood glucose, mice were i.p injected with insulin at a dose of $0.75 \mathrm{U} / \mathrm{kg}$ body weight. Blood glucose was then measured from the tail tip using a One Touch Ultra glucometer (LifeScan, Milpitas, CA, USA). We used colorimetry-based assays to measure serum non-esterified fatty acids (Wako Life Sciences), cholesterol (Wako Life Sciences) and total triglycerides (Thermo Scientific) and the Leptin ELISA kit is from Sigma-Aldrich. We dissected out the liver, BAT, epididymal WAT (eWAT) and inguinal WAT (iWAT) for subsequent analyses.

\section{Cell culture}

3T3-L1 cells were maintained in Dulbecco's modified Eagle's medium (DMEM) supplemented with 10\% calf serum and $1 \%$ penicillin/streptomycin (antibiotics) until confluency. After 2 days of confluence (Day 0), cells were induced to differentiate into adipocytes in DMEM containing 10\% fetal bovine serum (FBS), antibiotics and the standard cocktail of $0.5 \mathrm{mM}$ isobutyl1-methylxanthine, $1 \mu \mathrm{M}$ dexamethasone and $1.7 \mu \mathrm{M}$ insulin. Starting at Day 3, cells were maintained in DMEM containing $10 \%$ FBS and $0.425 \mu \mathrm{M}$ insulin, which was changed every 2 days. On Day 6, cells were fixed in $4 \%$ paraformaldehyde followed by either BODIPY and DAPI or Oil Red O staining. To assess the effects of Cbp and p300 on adipogenesis and browning, cells were treated with a selective $\mathrm{CBP} / \mathrm{p} 300$ inhibitor (A485) or an inactive mimic (A486) (Lasko et al. 2017) at $3 \mu \mathrm{M}$ either upon induction (Day 0) or after differentiation (Day 9) for $24 \mathrm{~h}$.

\section{Gene expression analysis}

We homogenized tissues and cells in TRIzol (Thermo Fisher) and isolated total RNA using the NucleoSpin RNA set for Nucleozol kit (Macherey-Nagel) and prepared cDNA using $1 \mu \mathrm{g}$ of total RNA with the High-Capacity cDNA Kit (Applied Biosystems). We then measured gene expression by Real-time PCR (qPCR) using GoTaq qPCR master mix (Promega). We calculated relative gene expression using the $\Delta \Delta$ Ct methods with ribosomal protein L23 (Rpl23) and cyclophilin $\mathrm{A}(\mathrm{CypA})$ as the reference genes in the tissues and cells respectively.

\section{Histology}

Tissues were fixed in $10 \%$ buffered formalin and embedded in paraffin. We sectioned the paraffin-embedded tissues $(\sim 8 \mu \mathrm{M})$ and stained with hematoxylin and eosin (H\&E). We analyzed and took images using the NIS Elements imaging software (Nikon instruments). Adipocyte size was measured using NIH Image J software (version 1.49t).

\section{Statistical analysis}

We used GraphPad Prism 6 (GraphPad Software) for all analyses and determined statistical significance at $P \leq 0.05$. All data points are presented as means \pm standard error of means (s.E.M.).

\section{Results}

\section{Adipose loss-of-function of $\mathrm{Cbp}$ or $\mathrm{p} 300$ has minimal effects on obesity and glucose homeostasis}

A possible role of CBP in energy metabolism has been previously suggested by the lean phenotype in $C b p$ heterozygous mice $\left(\mathrm{Cbp}^{+/-}\right)$(Yamauchi et al. 2002), but it is unclear whether this was directly caused by alterations in adipose plasticity or was secondary to changes in other tissues. Whole-body deletion of the $\mathrm{CH} 1$ domain in $C b p$ or $p 300$ results in better metabolic outcomes with less adiposity (Bedford et al. 2011). However, it remains unclear whether $\mathrm{CBP} / \mathrm{p} 300$, the key acetyltransferases, regulate adipose plasticity and whether their adipose functions directly underpin the systemic metabolic phenotypes. We first examined the expression of Cbp and p300 in the context of fat remodeling, either cold-induced browning or HFD-induced obesity, and observed different patterns in their depot-specific alterations (Fig. 1A and B). For example, cold challenge downregulated $C b p$ in iWAT 
and BAT but not in eWAT, whereas $p 300$ was repressed in BAT but induced in eWAT. HFD feeding induced p300 in eWAT and iWAT but not in BAT. These data suggest the distinct, depot-specific functions of Cbp and p300 in fat remodeling.

To further understand their functions in fat remodeling, we conditionally ablated $\mathrm{Cbp}$ or p300 in adipose tissues by crossing Cbpflox or $p 300$ flox with adipoq-cre mice resulting in Cbpflox/flox $\left(C b p^{F / F}\right)$ controls or Cbpflox/flox, adipoq-Cre (Cbp-AKO) and p300flox/flox $\left(p 300^{F / F}\right)$ controls or $p 300^{f l o x} /$ flox, adipoq-Cre (p300-AKO) mice respectively. This strategy resulted in successful deletions of exon 9 of both proteins, which encodes the catalytic domain (Supplementary Fig. 1, see section on supplementary data given at the end of this article) (KangDecker et al. 2004, Kasper et al. 2006). Surprisingly, despite the crucial functions of CBP in transcriptional regulation and in chromatin remodeling, loss of Cbp showed no effect on body weight (Fig. 2A), fat content (Fig. 2B and C),
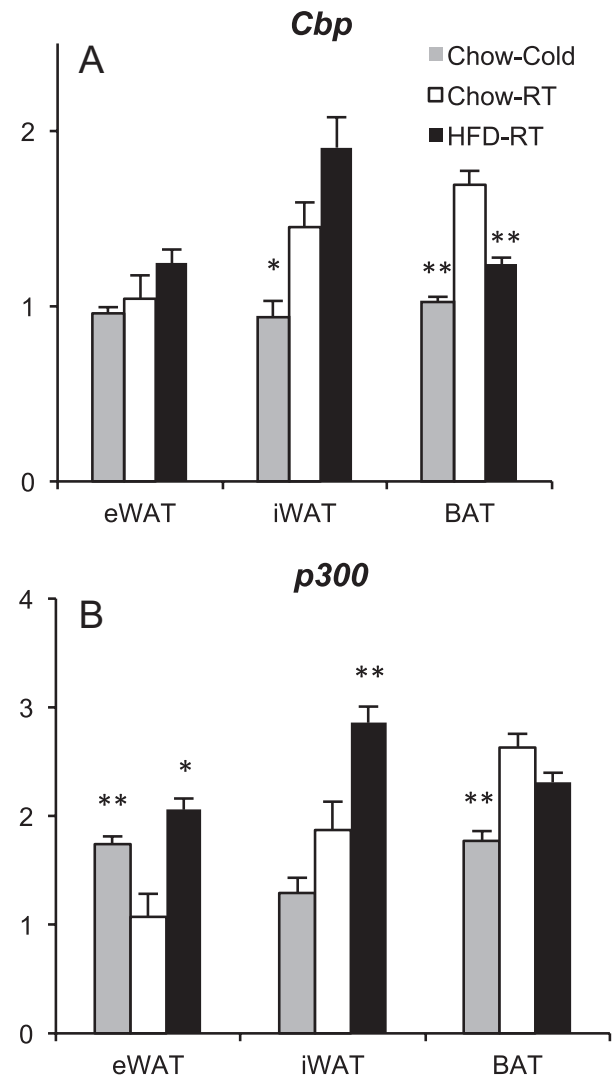

\section{Figure 1}

Depot-specific changes of $\mathrm{Cbp}$ and p300 expression during fat remodeling. Male WT C57BL/6 mice were either induced obesity by HFD feeding (HFD-RT) or induced brown remodeling by exposure to chronic cold ( $4^{\circ} \mathrm{C}$ for 4 days). The expression of $\mathrm{Cbp}$ (A) and $p 300$ (B) in different depots was analyzed by qPCR. Data are presented as mean \pm S.E.M., $* P<0.05$ and $* * P<0.01$ vs control group (Chow-RT), $n=6 /$ group.

(c) 2019 Society for Endocrinology Published by Bioscientifica Ltd. Printed in Great Britain glucose tolerance (Fig. 2D) or insulin sensitivity (Fig. 2E). Ablation of p300 phenocopied the minimal effects on body weight and composition and on glucose homeostasis (Fig. 2F, $\mathrm{G}$ and $\mathrm{H}$, and data not shown). In addition, their effects were not sexually dimorphic since they were recapitulated in females. Therefore, CBP and p300 seem dispensable in the maintenance of normal adipose functions, and the antiobesity effects in their whole-body partial loss of functions are unlikely to originate from adipose tissues.

\section{Loss of Cbp, but not $\mathrm{p} 300$, promotes browning preferentially in subcutaneous white fat}

Since protein deacetylase SirT1 gain-of-function (Qiang et al. 2012) and PPARy deacetylation (Kraakman et al. 2018) promote adipose brown remodeling, we asked whether loss of the acetyltransferase of PPAR $\gamma, \mathrm{CBP}$ or p300 could produce a similar browning phenotype. To this end, we examined the responses of $C b p-A K O$ or $p 300-A K O$ mice to cold exposure. Cold treatment had the same effects on body temperature (Fig. 3A), body weight (Fig. 3B) and epididymal (eWAT) and inguinal (iWAT) adipose tissue mass (Fig. 3C) in the $C b p-A K O$ mice compared to the $C b p^{F / F}$ control group. We followed up with molecular assessment by measuring the gene expression levels of browning and pan-adipocyte markers in iWAT and eWAT after cold treatment. Despite the identical core body temperatures of the Cbp-AKO mice and the control mice, the expression of browning markers such as Ucp1, Dio2, Elovl3 and Cox7a1 in the iWAT of the knockout mice was surprisingly upregulated (Fig. 3D). Similar to the observations in SirT1 gain of functions (Qiang et al.2012) or PPAR $\gamma$ deacetylation mouse models (Kraakman et al. 2018), the selective regulation of brown genes was recapitulated in the $C b p-A K O$ mice as the pan-adipocyte markers were not affected in their iWAT in response to cold exposure (Fig. 3E). Additionally, the browning effect of $C b p$ ablation is depot specific. In the eWAT from $C b p$ - $A K O$ mice, we observed a predominant downregulation of most of the browning markers (Fig. 3F). However, given the extremely low thermogenic capacity of eWAT, this observed decrease of browning is unlikely to significantly compromise iWAT thermogenesis. Pan-adipocyte markers were mildly affected with a downregulation of Adiponectin and Glut4 in the eWAT of Cbp-AKO mice (Fig. 3G). The effects of $C b p$ ablation in BAT were largely blunted during cold challenge (Fig. 3H and I). Regardless, the white adipocyte-enriched genes Adipsin and Resistin were repressed by Cbp ablation in both eWAT and BAT (Fig. 3G and I), in line with its browning function in iWAT. Taken together, the data demonstrated a depot-specific effect of Cbp in fat remodeling. 
A

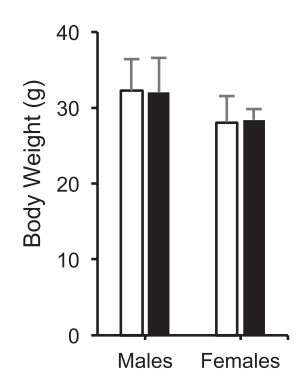

B

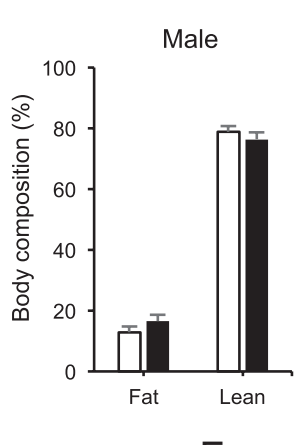

C

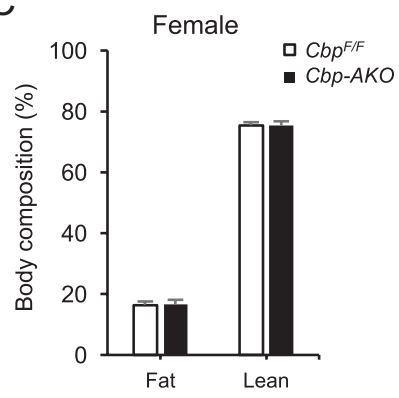

E

ITT

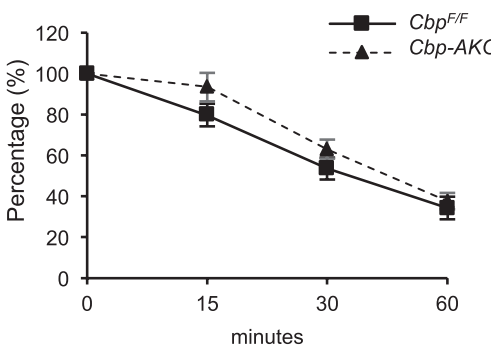

$\mathrm{H}$

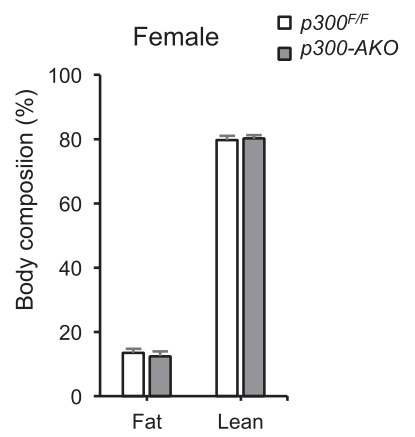

Figure 2

Adipose loss of $\mathrm{Cbp}$ or $p 300$ has no effect on adiposity or glucose metabolism. Six-month-old mice maintained on regular chow. (A, B, C, D and E) in Cbp-AKO and control mice, (A) body weight, ( $B$ and $C$ ) body fat composition in males and females ( $N=8,7$ males, 14, 15 females), (E) glucose tolerance test and $(\mathrm{F})$ insulin tolerance test. (F, $\mathrm{G}$ and $\mathrm{H})$ In $p 300-A K O$ and $p 300^{\mathrm{F} / \mathrm{F}}$ mice, $(\mathrm{F})$ body weight, $(\mathrm{G}$ and $\mathrm{H})$ body fat composition in males and females ( $N=5,4$ males; 4,6 females). Data are presented as mean \pm S.E.M.
In parallel, we exposed $p 300-A K O$ to the cold and observed the similar blunted effects on body temperature (Fig. 4A), body weight (Fig. 4B) and fat pat sizes (Fig. 4C) relative to the $p 300 p^{F / F}$ control mice. In contrast to $C b p-A K O$ mice, ablation of p300 in fat showed minimal effects on adipocyte gene expression. Neither brown markers nor panadipocyte genes in iWAT, eWAT or BAT were significantly altered in the $p 300-A K O$ (Fig. 4D, E, F, G, H and I). The blunted effects of p300 deletion were not caused by compensation from Cbp as it was not upregulated in any of the fat depots. Though CBP and p300 tend to be considered functionally redundant, we have shown that p300 is dispensable for adipose development and brown remodeling.

\section{Cbp deficiency reduces adiposity and promotes browning in IWAT under HFD conditions}

Given the significant browning in the iWAT of $C b p-A K O$ mice, we asked whether adipose loss of $C b p$ could protect from DIO and the associated insulin resistance. We fed
$C b p-A K O$ and $C b p^{F / F}$ (control) mice a HFD for 12 weeks. While they had the same body weight (Fig. 5A), Cbp-AKO mice had slightly lower fat composition (Fig. 5B), and their iWAT and eWAT fat pads were reduced by about $40 \%$ relative to the control littermates (Fig. 5C). The reduced iWAT and eWAT were caused by the inhibition of adipocyte hypertrophy rather than hyperplasia as the adipocytes from the $C b p-A K O$ mice were smaller than those from the control mice when maintained on a HFD, particularly in iWAT (Fig. 5D and E). Moreover, given the inhibition of hypertrophic obesity, we expected to see metabolic improvements in the knockouts. However, the $C b p-A K O$ mice surprisingly did not show significant improvements in glucose tolerance (Fig. 5F) or insulin sensitivity (not shown).

Since Cbp ablation promoted brown remodeling of iWAT in the $C b p-A K O$ mice upon cold exposure, we asked whether browning could be adapted in these knockout mice as a protective mechanism from DIO. Their gene expression profile in the eWAT and iWAT was consistent 
A

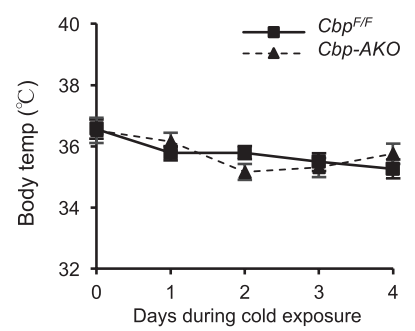

D

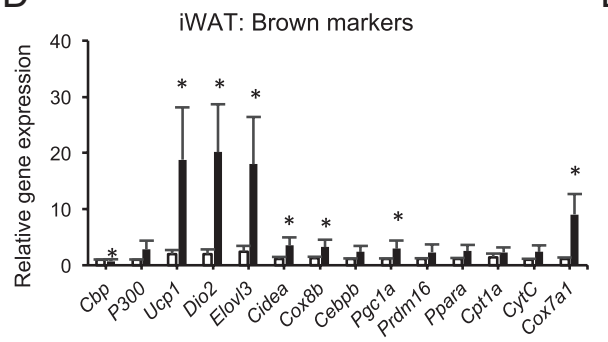

$\mathrm{F}$

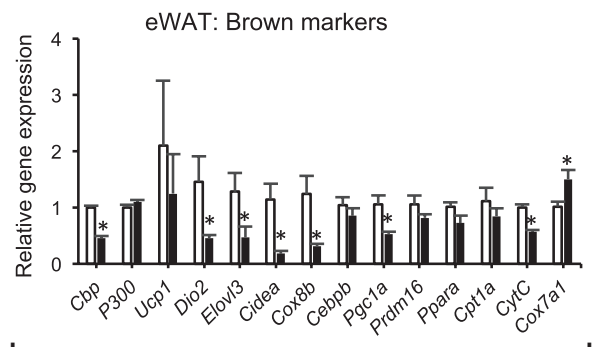

$\mathrm{H}$

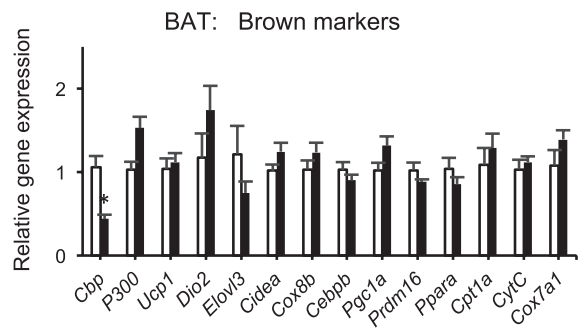

B

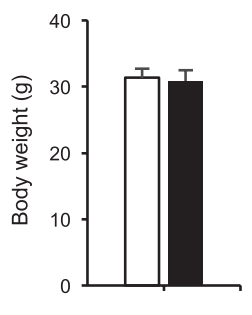

E

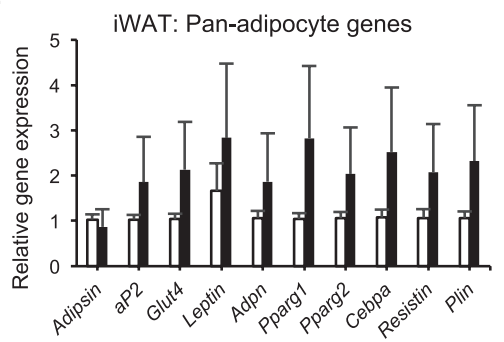

G

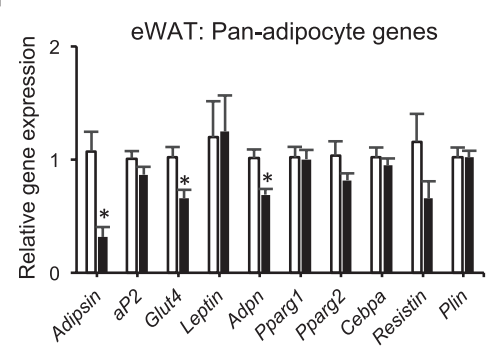

\section{I}
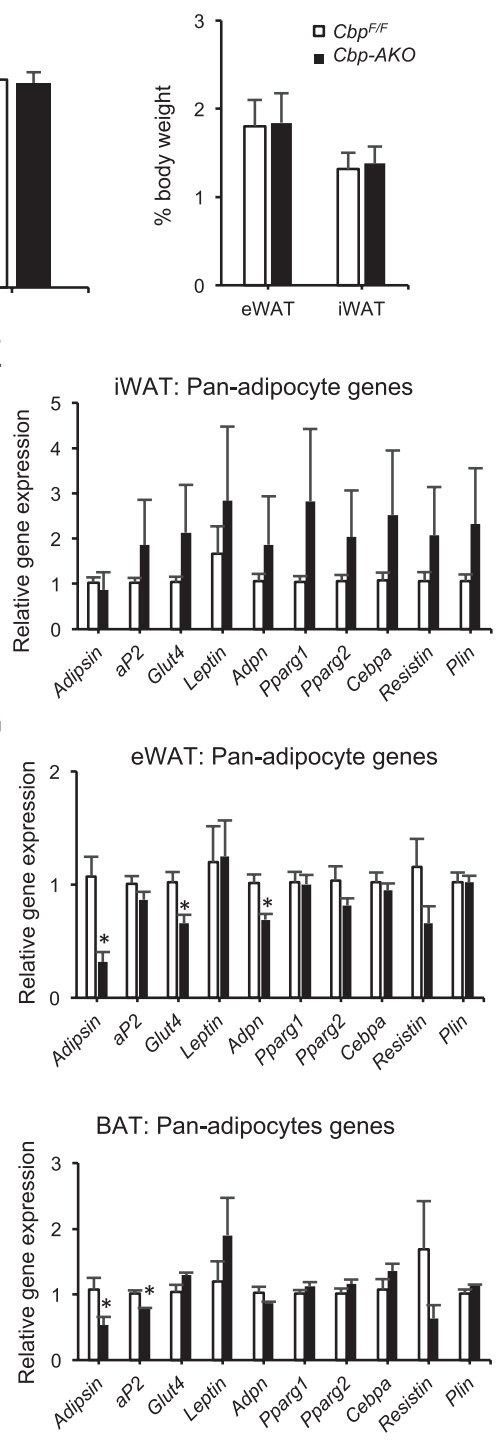

WAT: Pan-adipocyte genes
Figure 3

Loss of $C b p$ in adipose induces brown remodeling selectively in subcutaneous WAT after cold exposure. 6-month-old male $\mathrm{Cbp}$-AKO and $\mathrm{Cbp}$ F/F control mice maintained on regular chow and housed at $4^{\circ} \mathrm{C}$ for 4 days. (A) Core body temperature; (B) body weight; (C) adipose mass; real-time $\mathrm{QPCR}$ analysis of browning genes and regulators $(D, F$ and $H)$ and adipogenic genes $(E, G$ and I) from iWAT, eWAT and BAT respectively of Cbp-AKO compared to $C b p^{F / F}$ controls $(N=6,6)$.

Data are presented as mean \pm S.E.M. and * denotes a statistical significance at a $P$ value $\leq 0.05$. with the trends and patterns observed in those tissues after cold exposure. In response to HFD feeding, the upregulation of brown markers in the iWAT was more pronounced (Fig. 5G). For instance, Elovl3 showed the highest increase of over 100-fold. Ucp1 and Cox7a1 had a 12-fold increase, and Cidea and Cox8b had a 5-fold increase in the $C b p-A K O$ compared to the controls (Fig. 5G). Furthermore, the expression of adipocyte genes related to lipogenesis and the white adipocyte-enriched genes such as Adipsin, Glut4, Cebpo, Srebf1 and Adiponectin decreased by $20-50 \%$ in the Cbp-AKO mice (Fig. $5 \mathrm{H}$ ). In contrast to its effects in iWAT, ablation of Cbp yielded only mild, mixed effects in eWAT (Fig. 5I and J) and BAT (Supplementary Fig. 2). Moreover, ablation of p300 in fat showed minimal effects on body weight, fat composition, glucose tolerance, insulin sensitivity and fat remodeling
(Fig. 6), which further supports its dispensable role in fat. Overall, loss of Cbp, but not p300, in adipocytes induced striking brown remodeling (or anti-whitening) of iWAT in DIO without any significant improvement in glucose homeostasis.

\section{Combined loss of Cbp and p300 leads to severe lipodystrophy}

Upon observing the absence of metabolic changes in the $C b p-A K O$ and $p 300-A K O$ mice, we questioned whether it was possible that one protein was compensating for the loss of the other. As a result, we generated adipose-specific double-knockout mice, Cbp/p300-AKO, to evaluate the impact of such mutation on adipose remodeling. However, the double knockouts appeared at a much 
A

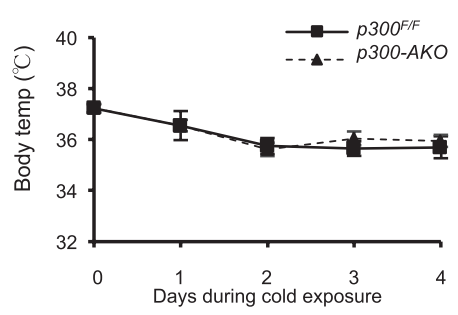

D

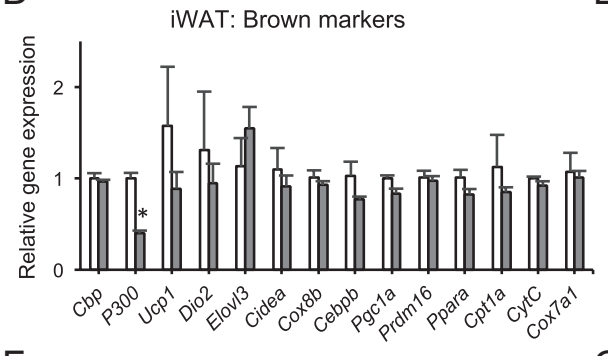

F

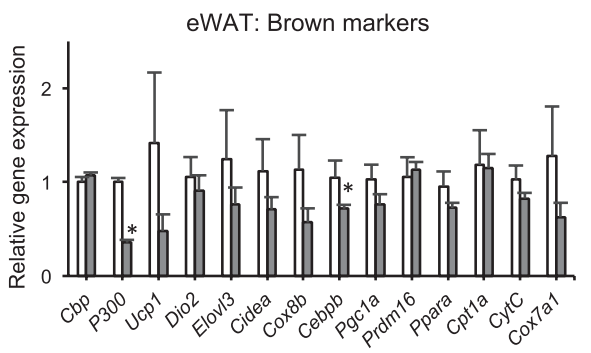

$\mathrm{H}$

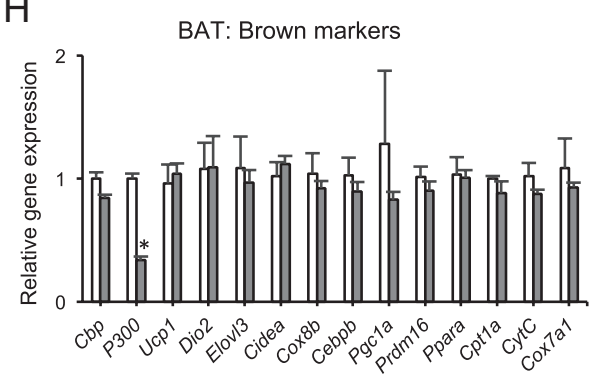

B

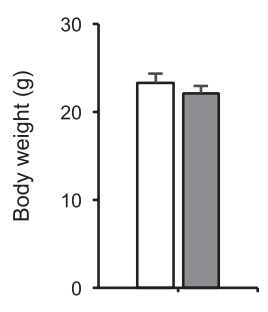

E
C
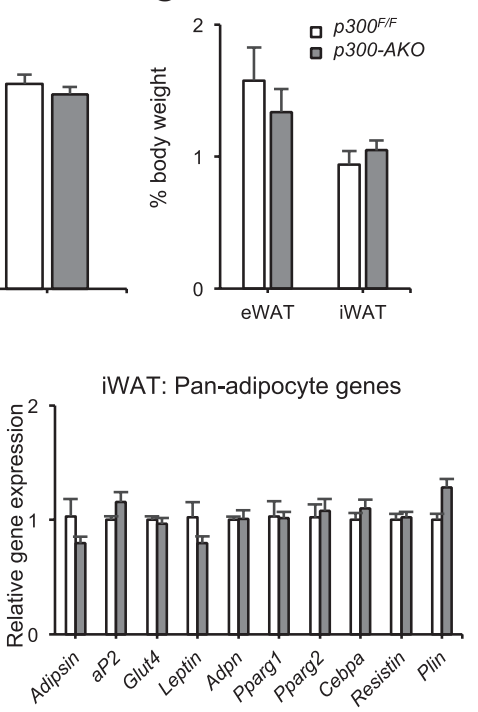

G

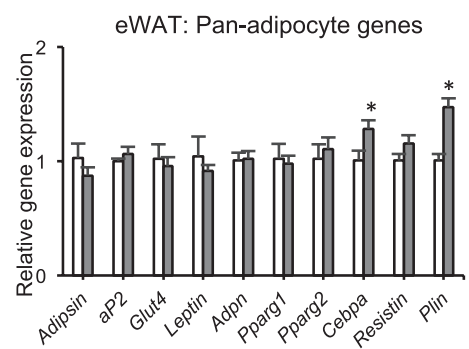

I

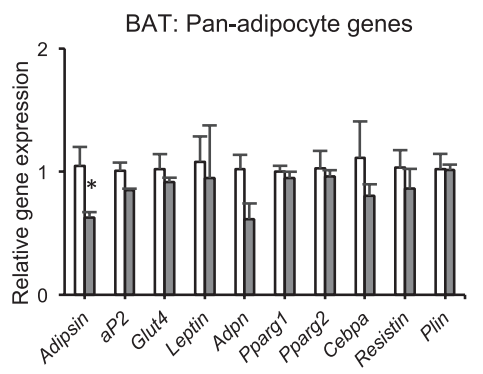

\section{Figure 4}

Loss of $p 300$ has minimal effect on cold-induced brown remodeling. Six-month-old male $p 300-A K O$ and $p 300^{\mathrm{F} / \mathrm{F}}$ controls mice maintained on regular chow and housed at $4^{\circ} \mathrm{C}$ for 4 days. (A) Core body temperature; (B) body weight; (C) adipose mass; real-time $\mathrm{QPCR}$ analysis of browning genes and regulators $(D, F$ and $H)$ and adipogenic genes $(E, G$ and I) from iWAT, eWAT and BAT respectively of p300-AKO compared to $p 300^{\mathrm{F} / \mathrm{F}}$ controls $(N=4,6)$. Data are presented as mean \pm S.E.M. and *denotes a statistical significance at a $P$ value $\leq 0.05$. lower frequency than the expected Mendelian ratio (Supplementary Table 1). This partial embryonic lethality could be explained by the activation of adiponectin-cre recombinase in the heart during development (Lee et al. 2013) rather than defects in adipose tissue. The viable double knockouts appeared normal at birth but gradually developed larger abdomens than the controls did. When they reached adulthood, their body weight was lower than that of the controls (Fig. 7A), and they developed typical characteristics of severe lipodystrophy (Wang et al. 2013) including hyperglycemia and dyslipidemia (Fig. 7B, $\mathrm{C}, \mathrm{D}$ and $\mathrm{E})$. The increase in cholesterol mainly occurred due to an increase in LDL (Supplementary Fig. 3). Additionally, we observed complete absence of fat across the body (Fig. 7G). Their livers were about 4 -fold larger than those of the control mice and were severely steatotic (Fig. 7F, G and H). As a consequence of their loss of fat, the double knockouts had only trace levels of adipokines including leptin, adipsin and adiponectin (Fig. 7I and J). Furthermore, HFD feeding worsened, instead of rescued, the lipodystrophy in Cbp/p300-AKO (Fig. 7K). Thus, CBP and p300 are essential for normal adipose development.

\section{Pharmacological targeting of Cbp and p300 impairs adipocyte formation and maintenance}

$\mathrm{CBP} / \mathrm{p} 300$ are versatile proteins functioning as co-activators, adaptors and intrinsic acetyltransferases. Deletion of their $\mathrm{CH} 1$ domains while maintaining intact HAT (histone acetyltransferase) domains improved metabolic control 
A

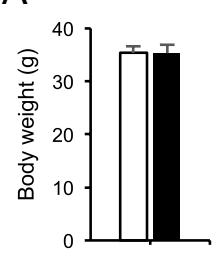

B

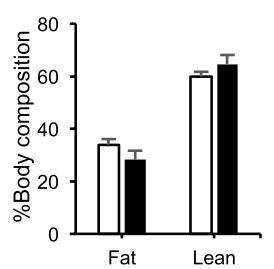

E

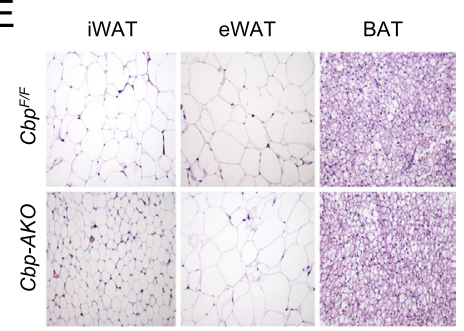

G

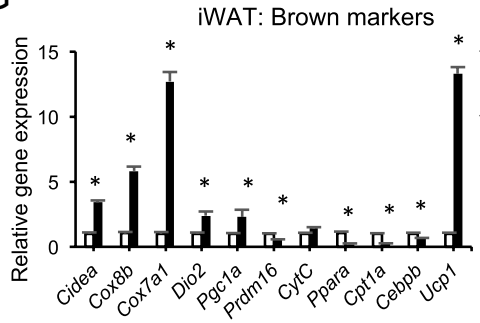

।

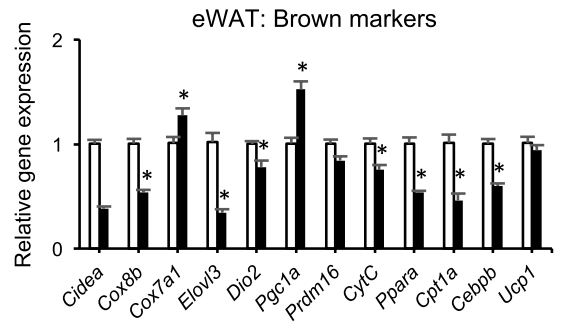

C

$\mathrm{F}$
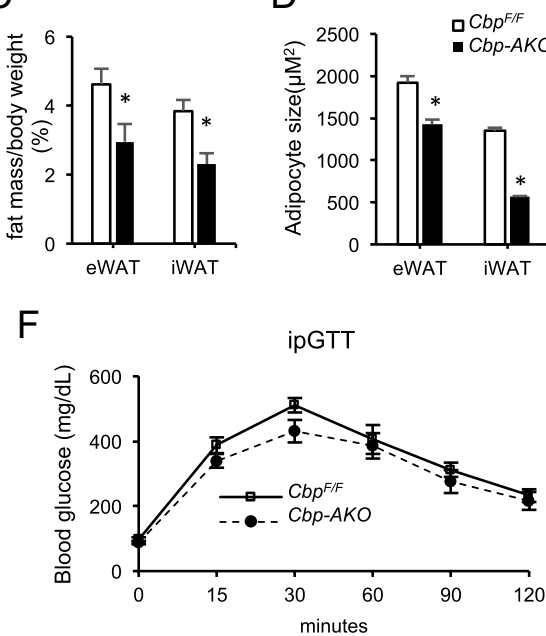

$\mathrm{H}$
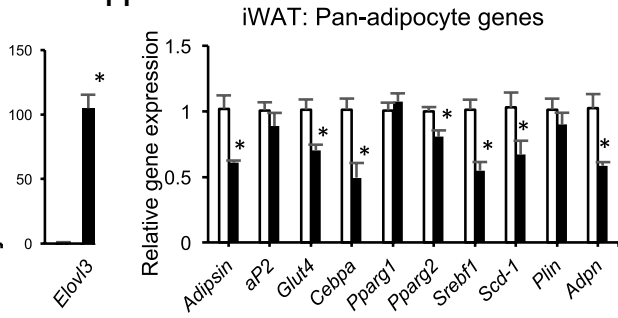

$\mathrm{J}$

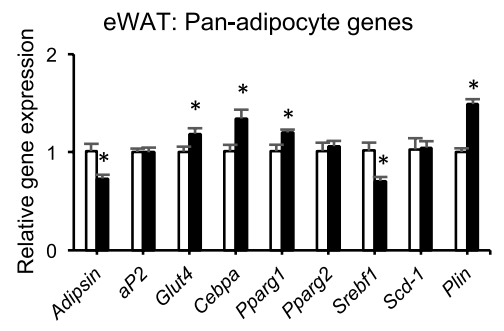

\section{Figure 5}

Adipose deficiency of $\mathrm{Cbp}$ reduces adiposity and induces brown remodeling in subcutaneous WAT after diet-induced obesity. Male $C b p-A K O$ and $\mathrm{Cbp} F / F$ mice were maintained on HFD for 12 weeks. (A) Body weight; (B) body composition; (C) eWAT and iWAT adipose mass; (D)

quantification of the average adipocyte size from eWAT and IWAT ( $N=6,6$ males). (E)

Representative histological sections of eWAT, IWAT and BAT stained with hematoxylin and eosin (H\&E). (F) Intraperitoneal glucose tolerance test from $C b p-A K O$ and $C b p F / F(N=7,14) .(G, H, I$ and J) Real-time $\mathrm{QPCR}$ analysis of browning genes and regulators ( $\mathrm{G}$ and $\mathrm{I})$ and adipogenic genes ( $\mathrm{H}$ and J) from iWAT and eWAT respectively of $C b p-A K O$ and $\operatorname{Cbp} F / F(N=6,6)$. Data are presented as mean \pm S.E.M. and * denotes a statistical

significance at a $P$ value $\leq 0.05$. A full colour version of this figure is available at https://doi. org/10.1530/JOE-18-0361. but did not impair adipogenesis (Bedford et al. 2011). We tested whether their HAT activity is required for adipocyte formation. A potent and selective inhibitor of CBP and p300 HAT domains, A485, has been developed for cancer treatment (Lasko et al. 2017). We treated 3T3-L1 cells with A485 starting 2 days prior to the induction of differentiation and found that the inhibition of Cbp and p300 HAT activities suppressed adipogenesis efficiency, as demonstrated through reduced lipid accumulation (Fig. 8A) and a corresponding decrease of genes involved in adipocyte differentiation and lipid synthesis such as Cebpo, Ppary1, aP2, Srebpf and Plin (Fig. 8B) in comparison to the control compound A486-treated cells. Furthermore, from a therapeutic point of view, we determined the effects of A485 on existing adipocytes. We treated fully differentiated 3T3-L1 adipocytes (9 days post-induction) with A486 for $24 \mathrm{~h}$. Strikingly, inhibition of HAT activities of Cbp and p300 suppressed the expression of all the pan-adipocyte genes (Ppary1, Ppary2, Adiponectin, Adipsin, aP2 and Perilipin) and lipogenic genes (Srebf1, Scd1) that were examined (Fig. 8C). Interestingly, this suppression seems to occur downstream of $\mathrm{C} / \mathrm{ebp} \beta$ in the adipogenic cascade. Due to the dedifferentiation of adipocytes, browning adipocyte markers were also downregulated (Fig. 8D). Together, these data demonstrate that HAT activities of CBP and p300 are required for adipocyte differentiation as well as the maintenance of mature adipocyte functions.

\section{Discussion}

Increasing the activity of deacetylases, such as SirT1, through pharmacological or genetic manipulation induced robust browning of WAT, which in turn resulted in healthier metabolic outcomes marked by reduced body weight and improved glucose metabolism (Minor et al. 2011, 
A
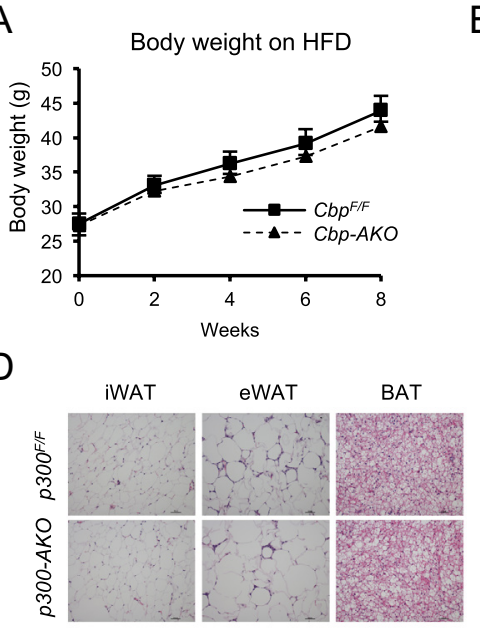

F

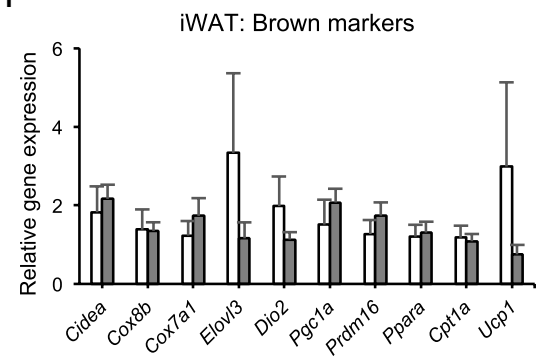

$\mathrm{H}$

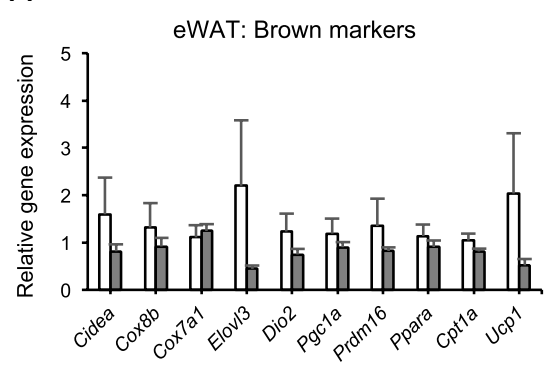

B

E
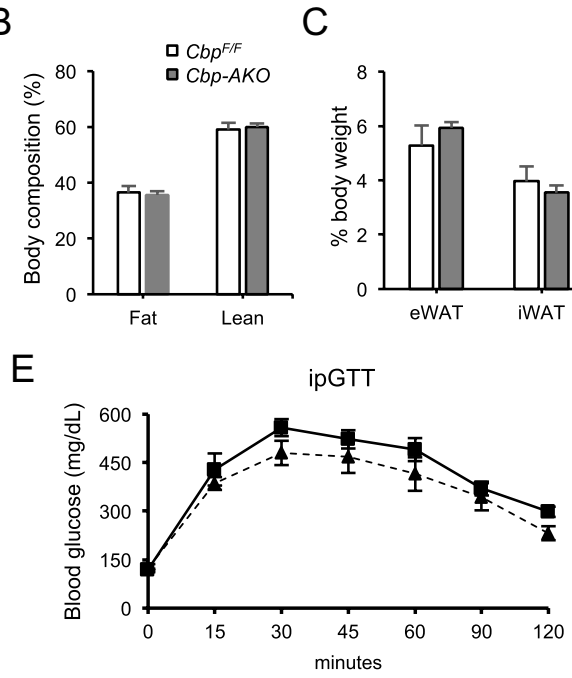

G

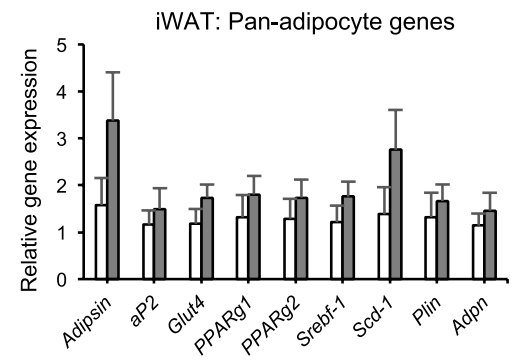

I

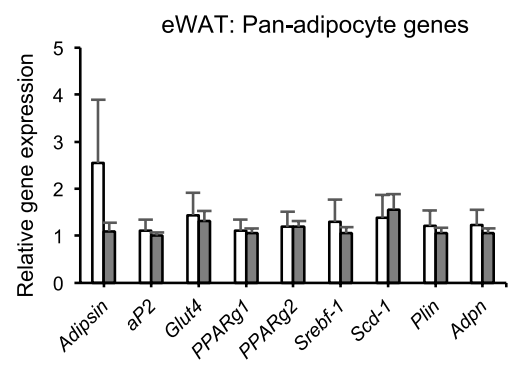

Figure 6

Adipose deficiency of $p 300$ does not affect adiposity and metabolism in diet-induced obesity. Male $p 300-A K O$ and control mice were maintained on HFD for 8 weeks. (A) Body weight curve during HFD feeding; (B) body composition; (C) eWAT and iWAT adipose mass; (D) representative histological sections of eWAT, iWAT and BAT stained with hematoxylin and eosin. (E) Intraperitoneal glucose tolerance test; (F, G, H and I) Real-time GPCR analysis of browning genes and regulators $(\mathrm{F}$ and $\mathrm{H})$ and adipogenic genes ( $\mathrm{G}$ and I) from iWAT and eWAT respectively $(N=5,5)$. Data are presented as mean \pm S.E.M. A full colour version of this figure is available at https://doi. org/10.1530/JOE-18-0361.
Qiang et al. 2012, Mitchell et al. 2014). Heterozygous deletion of $C b p$ protected mice from DIO and resulted in better glucose tolerance (Yamauchi et al. 2002). Here, we report that adipose-specific loss of $C b p(C b p-A K O)$ leads to selective browning in inguinal WAT (iWAT) but not in visceral WAT (eWAT) while adipose-specific loss of p300 (p300-AKO) has minimal effects on adipose tissue plasticity after cold exposure. After 3 months of HFD feeding, $C b p-A K O$ mice, but not $p 300-A K O$, exhibited reduced adiposity and enhanced expression of a brown fat gene signature profile in iWAT without significant improvement of glucose homeostasis. Furthermore, we showed that double knockout mice (Cbp/p300-AKO) developed severe lipodystrophy marked by lack of adipose tissue, hepatomegaly, hyperglycemia and hyperlipidemia. Our results delineate the distinct functions of CBP and p300 in regulating WAT remodeling as well as their importance in adipose development.

Several studies have described mouse models exhibiting browning of WAT accompanied by improved glucose tolerance and insulin sensitivity (Harms \& Seale 2013). One of the intriguing discoveries from our study is that browning of WAT in the Cbp-AKO mice can occur without changes to body weight and glucose metabolism, even under obesogenic conditions. This finding is discordant with the current assumption that browning of WAT usually correlates with an improved metabolic profile. Recent studies have identified alternative mechanisms to induce thermogenesis independent of Ucp1 activation (Ukropec et al. 2006, Anunciado-Koza et al. 2008, Kazak et al. 2015, Ikeda et al. 2017). Among the possibilities is increased calcium cycling in beige fat 
A
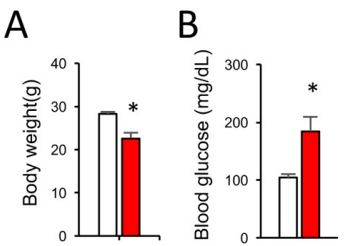

G

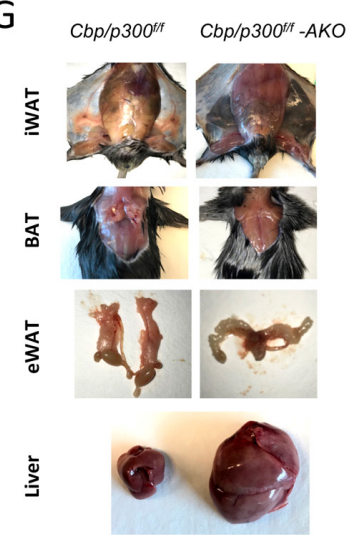

K

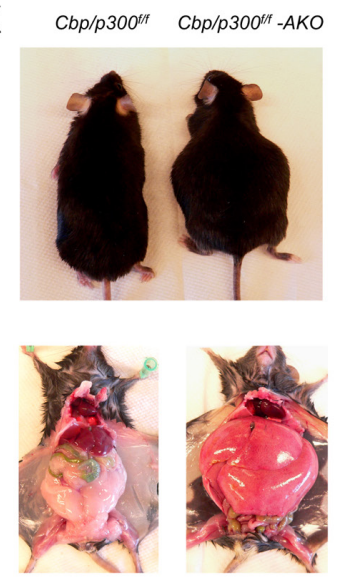

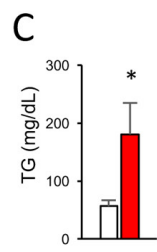

D

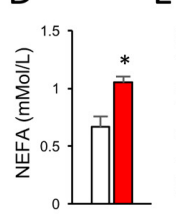

E

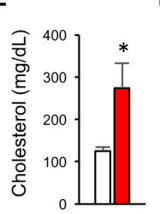

$\mathrm{F}$

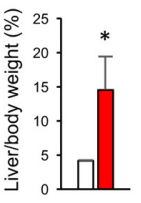

$\mathrm{H}$

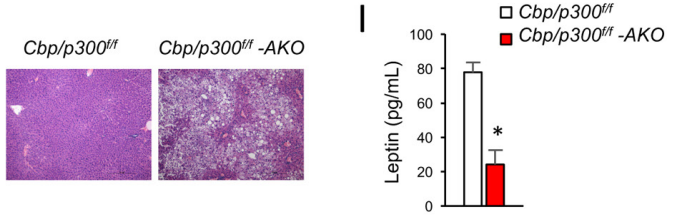

J

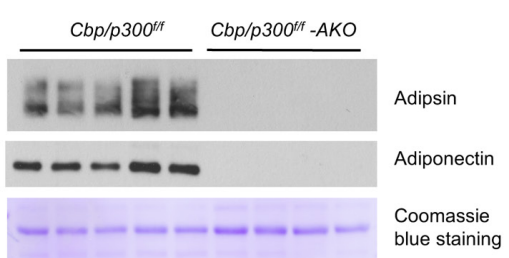

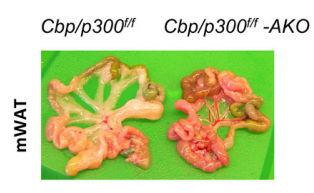

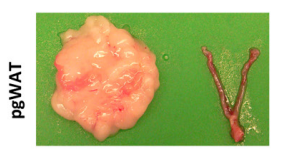

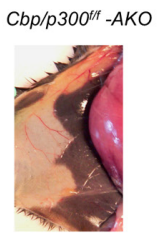
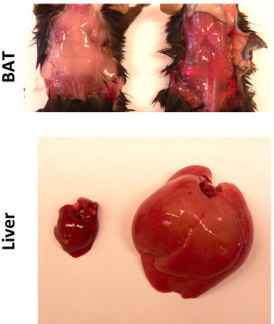

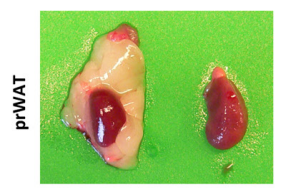

\section{Figure 7}

Loss of $C b p$ and $p 300$ leads to severe lipodystrophy. In chow-fed Cbp/p300-AKO and CbpF/F/p300F/F controls, (A) body weight, (B, C, D and E) blood glucose, serum triglycerides (TG), free fatty acids and total cholesterol measurements $(N=5,4)$; (F) Liver sizes; $(G)$ anatomic comparison of adipose tissues and liver; (H) histological analysis of livers by H\&E staining; (I) ELISA measurement of serum leptin levels; (J) Western blotting analyses of serum adipsin and adiponectin. (K) Anatomic analyses of $\mathrm{Cbp} /$ p300-AKO and Cbp/F/p300 F/F mice in diet-induced obesity. Data are presented as mean \pm S.E.M. and * denotes a statistical significance at a $P$-value $\leq 0.05$. A full colour version of this figure is available at https://doi.org/10.1530/JOE-18-0361. via the Serca2-Ryr pathway, which allowed for Prdm16 transgenic mice on a Ucp1-null background to increase energy expenditure and improve glucose metabolism. This trend was maintained even after HFD feeding (Ikeda et al. 2017). Alternatively, increasing creatine cycling or the phosphorylation of creatine after beta-adrenergic activation led to increased oxygen consumption and heat production in beige adipocytes and resulted in protection from DIO (Kazak et al. 2015, 2017). It is possible that such alternative thermogenic pathways could be affected and thus compromises the metabolic benefits of Ucp1dependent brown remodeling in iWAT of $C b p$-AKO mice.

Homozygous mice carrying a deletion of the $\mathrm{CH} 1-$ domain in either Cbp or p300 showed reduced body weight and adiposity but no significant difference in fasting blood glucose (Bedford et al. 2011). These results were attributed to a possible shift in white adipose function from energy

(c) 2019 Society for Endocrinology Published by Bioscientifica Ltd. Printed in Great Britain storage to expenditure; however, there were no defects in adipocyte differentiation (Bedford et al. 2011). Here, we show that this browning effect of Cbp deficiency is adipocyte autonomous rather than secondary to changes in other tissues, and is depot specific, as evidenced by the brown remodeling of iWAT but not eWAT in Cbp-AKO mice. In this regard, the functions of CBP and p300 are discrete, and the underlying mechanism is worthy of further investigation.

Embryonic fibroblasts from $\mathrm{Cbp}^{+/-}$mice expressed decreased adipogenesis relative to WT cells, buttressing their lean phenotype (Yamauchi et al. 2002). An overall blunted effect on adipogenesis in the $C b p-A K O$ is probably caused by the delayed deletion of Cbp by AdiponectinCre after the initiation of differentiation. Previous studies revealed that CBP and p300 played a role in promoting adipogenesis by acetylating the key adipogenic regulators, 
A

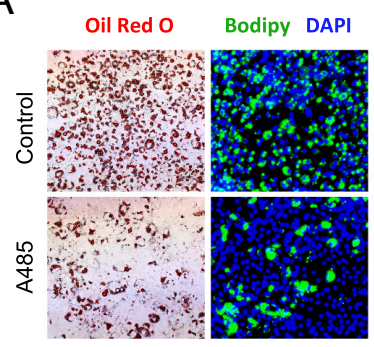

B

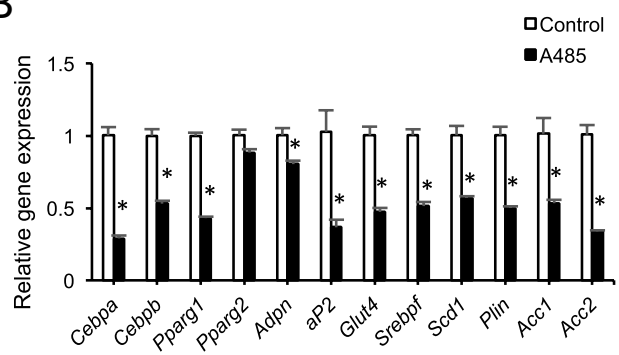

C

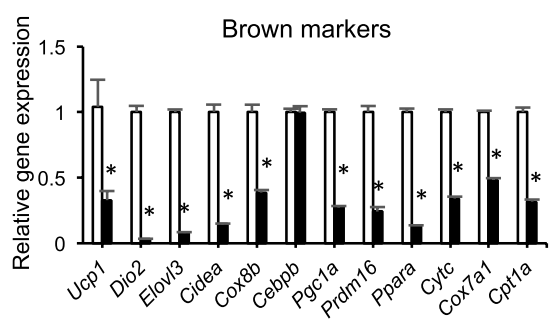

D

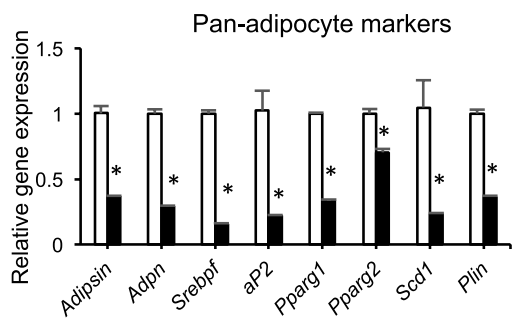

\section{Figure 8}

Inhibition of $\mathrm{Cbp}$ and p300 activity suppresses adipogenesis. (A) 3T3-L1 preadipocytes were treated with A486, a mimic (Control) or with the inhibitor (A485) at the induction of adipogenesis, Oil Red O (red) and BODIPY (green) counterstained with DAPI (blue) to assess differentiation efficiency by lipid accumulation. (B) Real-time qPCR analysis of genes involved in adipocyte differentiation upon treatment with or without inhibitor during induction. (C and D) Fully differentiated mature adipocytes were treated with A485 since Day 9 of differentiation for 3 days, (C) brown adipocyte genes and regulators and (D) pan-adipocyte genes by qPCR analysis. Data are presented as mean \pm S.E.M. and * denotes a statistical significance at a $P$ value $\leq 0.05$.
PPAR $\gamma$ and CEBP $\alpha$ in vitro (Chen et al. 2000, Erickson et al. 2001, Zhao et al. 2014). In line with this, inhibiting HAT activities of CBP and p300 in 3T3-L1 cells impaired adipogenesis, indicating an essential role of their acetyltransferase activity in adipocyte formation.

In contrast to single knockout mice ( $C b p-A K O$ or p300-AKO), a conspicuous feature of the double-knockout mice $(C b p / p 300-A K O)$ is severe lipodystrophy similar to other previously described lipodystrophy models (Shimomura et al. 1998, Kim et al. 2007, Cortés et al. 2009, Vernochet etal.2014), which points toward a compensatory effect between these two proteins in adipose development and lipid metabolism. It also implies a requirement of targeting both simultaneously for potential obesity treatment. In line with this, the HAT inhibitor A485 for both CBP and p300 causes dedifferentiation of the mature adipocyte. Moreover, A485 was discovered as a potential cancer drug and showed selective toxicity to tumor cells (Lasko et al. 2017). Obesity is known to increase risks of multiple cancers and an efficient intervention to target both is lacking. Notably, mice treated with A485 showed a significant decrease in body weight and weight loss reversal after suspension of the inhibitor treatment (Lasko et al. 2017). Therefore, targeting HAT activities of CBP and p300 may be harnessed for the treatment of cancer and obesity simultaneously.

Taken together, our data indicate that there are differential effects of CBP and p300 on adipose tissue remodeling. Loss of $\mathrm{CBP}$, but not p300, in adipose tissue reduces adiposity and regulates browning in a depotspecific manner. The regulation of adipocyte biology by CBP and p300 are discrete in their CH1 domain-mediated and HAT activity functions. Thus, understanding the precise mechanism and regulation of both CBP and p300 might be important in harnessing them as possible targets to treat obesity preferably in a depot-specific manner, especially with the identification of a promising selective $\mathrm{CBP} / \mathrm{p} 300$ inhibitor that can suppress cancer progression.

\section{Supplementary data}

This is linked to the online version of the paper at https://doi.org/10.1530/ JOE-18-0361.

\section{Declaration of interest}

The authors declare that there is no conflict of interest that could be perceived as prejudicing the impartiality of the research reported.

\section{Funding}

This work was supported by National Institutes of Health grants R00DK97455 (L Q) and R01DK112943 (L Q), Pilot and Feasibility funding to L Q from the Diabetes Research Center (P30 DK063608).

\section{Acknowledgements}

The authors thank members of the Qiang laboratory for valuable discussions, and Ana M Flete and Thomas Kolar for technical assistance.

\section{References}

Anunciado-Koza R, Ukropec J, Koza RA \& Kozak LP 2008 Inactivation of UCP1 and the glycerol phosphate cycle synergistically increases energy expenditure to resist diet-induced obesity. Journal of Biological Chemistry 283 27688-27697. (https://doi.org/10.1074/jbc.M804268200) 
Banks AS, Kon N, Knight C, Matsumoto M, Gutiérrez-Juárez R, Rossetti L, Gu W \& Accili D 2008 SirT1 gain of function increases energy efficiency and prevents diabetes in mice. Cell Metabolism 8 333-341. (https://doi.org/10.1016/j.cmet.2008.08.014)

Bedford DC, Kasper LH, Fukuyama T \& Brindle PK 2010 Target gene context influences the transcriptional requirement for the KAT3 family of CBP and p300 histone acetyltransferases. Epigenetics 5 9-15. (https://doi.org/10.4161/epi.5.1.10449)

Bedford DC, Kasper LH, Wang R, Chang Y, Green DR \& Brindle PK 2011 Disrupting the CH1 domain structure in the acetyltransferases СBP and p300 results in lean mice with increased metabolic control. Cell Metabolism 14 219-230. (https://doi.org/10.1016/j.cmet.2011.06.010)

Bordicchia M, Liu D, Amri E-Z, Ailhaud G, Dessì-Fulgheri P, Zhang C, Takahashi N, Sarzani R \& Collins S 2012 Cardiac natriuretic peptides act via p38 MAPK to induce the brown fat thermogenic program in mouse and human adipocytes. Journal of Clinical Investigation 122 1022-1036. (https://doi.org/10.1172/JCI59701)

Chalkiadaki A \& Guarente L 2012 High-fat diet triggers inflammationinduced cleavage of SIRT1 in adipose tissue to promote metabolic dysfunction. Cell Metabolism 16 180-188. (https://doi.org/10.1016/j. cmet.2012.07.003)

Chen S, Johnson BA, Li Y, Aster S, McKeever B, Mosley R, Moller DE \& Zhou G 2000 Both coactivator LXXLL motif-dependent and -independent interactions are required for peroxisome proliferatoractivated receptor gamma (PPARgamma) function. Journal of Biological Chemistry 275 3733-3736. (https://doi.org/10.1074/jbc.275.6.3733)

Cortés VA, Curtis DE, Sukumaran S, Shao X, Parameswara V, Rashid S, Smith AR, Ren J, Esser V, Hammer RE, et al. 2009 Molecular mechanisms of hepatic steatosis and insulin resistance in the AGPAT2-deficient mouse model of congenital generalized lipodystrophy. Cell Metabolism 9 165-176. (https://doi.org/10.1016/j. cmet.2009.01.002)

Coskun T, Bina HA, Schneider MA, Dunbar JD, Hu CC, Chen Y, Moller DE \& Kharitonenkov A 2008 Fibroblast growth factor 21 corrects obesity in mice. Endocrinology 149 6018-6027. (https://doi.org/10.1210/ en.2008-0816)

Eguchi J, Wang X, Yu S, Kershaw EE, Chiu, PC, Dushay J, Estall JL, Klein U, Maratos-Flier E \& Rosen ED 2011 Transcriptional control of adipose lipid handling by IRF4. Cell Metabolism 13 249-259. (https:// doi.org/10.1016/j.cmet.2011.02.005)

Erickson RL, Hemati N, Ross SE \& MacDougald OA 2001 p300 coactivates the adipogenic transcription factor CCAAT/enhancer-binding protein alpha. Journal of Biological Chemistry 276 16348-16355. (https://doi. org/10.1074/jbc.M100128200)

Feige JN, Lagouge M, Canto C, Strehle A, Houten SM, Milne JC, Lambert PD, Mataki C, Elliott PJ \& Auwerx J 2008 Specific SIRT1 activation mimics low energy levels and protects against diet-induced metabolic disorders by enhancing fat oxidation. Cell Metabolism $\mathbf{8}$ 347-358. (https://doi.org/10.1016/j.cmet.2008.08.017)

Gillum MP, Kotas ME, Erion DM, Kursawe R, Chatterjee P, Nead KT, Muise ES, Hsiao JJ, Frederick DW, Yonemitsu S, et al. 2011 SirT1 regulates adipose tissue inflammation. Diabetes 60 3235-3245. (https://doi.org/10.2337/db11-0616)

Guerra C, Koza RA, Yamashita H \& Walsh KKozak LP 1998 Emergence of brown adipocytes in white fat in mice is under genetic control. Effects on body weight and adiposity. Journal of Clinical Investigation 102 412-420. (https://doi.org/10.1172/JCI3155)

Harms M \& Seale P 2013 Brown and beige fat: development, function and therapeutic potential. Nature Medicine 19 1252-1263. (https://doi. org/10.1038/nm.3361)

He L, Sabet A, Djedjos S, Miller R, Sun X, Hussain MA, Radovick S \& Wondisford FE 2009 Metformin and insulin suppress hepatic gluconeogenesis through phosphorylation of CREB binding protein. Cell 137 635-646. (https://doi.org/10.1016/j.cell.2009.03.016)

He L, Naik K, Meng S, Cao J, Sidhaye AR, Ma A, Radovick S \& Wondisford FE 2012 Transcriptional co-activator p300 maintains basal hepatic gluconeogenesis. Journal of Biological Chemistry $\mathbf{2 8 7}$ 32069-32077. (https://doi.org/10.1074/jbc.M112.385864)

He L, Cao J, Meng S, Ma A, Radovick S \& Wondisford FE 2013 Activation of basal gluconeogenesis by coactivator p300 maintains hepatic glycogen storage. Molecular Endocrinology 27 1322-1332. (https://doi. org/10.1210/me.2012-1413)

Ikeda K, Kang Q, Yoneshiro T, Camporez JP, Maki H, Homma M, Shinoda K, Chen Y, Lu X, Maretich P, et al. 2017 UCP1-independent signaling involving SERCA2b-mediated calcium cycling regulates beige fat thermogenesis and systemic glucose homeostasis. Nature Medicine 23 1454-1465. (https://doi.org/10.1038/nm.4429)

Kang-Decker N, Tong C, Boussouar F, Baker DJ, Xu W, Leontovich AA, Taylor WR, Brindle PK \& van Deursen JMA 2004 Loss of CBP causes T cell lymphomagenesis in synergy with p27Kip1 insufficiency. Cancer Cell 5 177-189. (https://doi.org/10.1016/S1535-6108(04)00022-4)

Kasper LH, Fukuyama T, Biesen MA, Boussouar F, Tong C, de Pauw A, Murray PJ, van Deursen JMA \& Brindle PK 2006 Conditional knockout mice reveal distinct functions for the global transcriptional coactivators CBP and p300 in T-cell development. Molecular and Cellular Biology 26 789-809. (https://doi.org/10.1128/MCB.26.3.789809.2006)

Kasper LH, Lerach S, Wang J, Wu S, Jeevan T \& Brindle PK 2010 CBP/ p300 double null cells reveal effect of coactivator level and diversity on CREB transactivation. EMBO Journal 29 3660-3672. (https://doi. org/10.1038/emboj.2010.235)

Kazak L, Chouchani ET, Jedrychowski MP, Erickson BK, Shinoda K, Cohen P, Vetrivelan R, Lu GZ, Laznik-Bogoslavski D, Hasenfuss SC, et al. 2015 A creatine-driven substrate cycle enhances energy expenditure and thermogenesis in beige fat. Cell 163 643-655. (https://doi.org/10.1016/j.cell.2015.09.035)

Kazak L, Chouchani ET, Lu GZ, Jedrychowski MP, Bare CJ, Mina AI, Kumari M, Zhang S, Vuckovic I, Laznik-Bogoslavski D, et al. 2017 Genetic depletion of adipocyte creatine metabolism inhibits dietinduced thermogenesis and drives obesity. Cell Metabolism 26693. (https://doi.org/10.1016/j.cmet.2017.09.007)

Kim S, Huang L-W, Snow KJ, Ablamunits V, Hasham MG, Young TH, Paulk AC, Richardson JE, Affourtit JP, Shalom-Barak T, et al. 2007 A mouse model of conditional lipodystrophy. PNAS 104 16627-16632. (https://doi.org/10.1073/pnas.0707797104)

Kraakman MJ, Liu Q, Postigo-Fernandez J, Ji R, Kon N, Larrea D, Namwanje M, Fan L, Chan M, Area-Gomez E, et al. 2018 PPAR $\gamma$ deacetylation dissociates thiazolidinedione's metabolic benefits from its adverse effects. Journal of Clinical Investigation 128 2600-2612. (https://doi.org/10.1172/JCI98709)

Lagouge M, Argmann C, Gerhart-Hines Z, Meziane H, Lerin C, Daussin F, Messadeq N, Milne J, Lambert P, Elliott P, et al. 2006 Resveratrol improves mitochondrial function and protects against metabolic disease by activating SIRT1 and PGC-1alpha. Cell 127 1109-1122. (https://doi.org/10.1016/j.cell.2006.11.013)

Lasko LM, Jakob CG, Edalji RP, Qiu W, Montgomery D, Digiammarino EL, Hansen TM, Risi RM, Frey R, Manaves V, et al. 2017 Discovery of a selective catalytic p300/CBP inhibitor that targets lineage-specific tumours. Nature 550 128-132. (https://doi.org/10.1038/nature24028)

Lee KY, Russell SJ, Ussar S, Boucher J, Vernochet C, Mori MA, Smyth G, Rourk M, Cederquist C, Rosen ED, et al. 2013 Lessons on conditional gene targeting in mouse adipose tissue. Diabetes 62 864-874. (https:// doi.org/10.2337/db12-1089)

Mayoral R, Osborn O, McNelis J, Johnson AM, Oh DY, Izquierdo CL, Chung H, Li P, Traves PG, Bandyopadhyay G, et al. 2015 Adipocyte SIRT1 knockout promotes PPAR $\gamma$ activity, adipogenesis and insulin sensitivity in chronic-HFD and obesity. Molecular Metabolism 4 378-391. (https://doi.org/10.1016/j.molmet.2015.02.007)

Milne JC, Lambert PD, Schenk S, Carney DP, Smith JJ, Gagne DJ, Jin L, Boss O, Perni RB, Vu CB, et al. 2007 Small molecule activators of SIRT1 as therapeutics for the treatment of type 2 diabetes. Nature $\mathbf{4 5 0}$ 712-716. (https://doi.org/10.1038/nature06261) 
Minor RK, Baur JA, Gomes AP, Ward TM, Csiszar A, Mercken EM, Abdelmohsen K, Shin Y-K, Canto C, Scheibye-Knudsen M, et al. 2011 SRT1720 improves survival and healthspan of obese mice. Scientific Reports 1 70. (https://doi.org/10.1038/srep00070)

Mitchell SJ, Martín-Montalvo A, Mercken EM, Palacios HH, Ward TM, Abulwerdi G, Minor RK, Vlasuk GP, Ellis JL, Sinclair DA, et al. 2014 The SIRT1 activator SRT1720 extends lifespan and improves health of mice fed a standard diet. Cell Reports 6 836-843. (https://doi. org/10.1016/j.celrep.2014.01.031)

Moreno CL, Yang L, Dacks PA, Isoda F, Deursen JMAV \& Mobbs CV 2016 Role of hypothalamic creb-binding protein in obesity and molecular reprogramming of metabolic substrates. PLOS ONE 11 e0166381. (https://doi.org/10.1371/journal.pone.0166381)

Petrovic N, Walden TB, Shabalina IG, Timmons JA, Cannon B \& Nedergaard J 2010 Chronic peroxisome proliferator-activated receptor gamma (PPARgamma) activation of epididymally derived white adipocyte cultures reveals a population of thermogenically competent, UCP1-containing adipocytes molecularly distinct from classic brown adipocytes. Journal of Biological Chemistry $\mathbf{2 8 5}$ 7153-7164. (https://doi.org/10.1074/jbc.M109.053942)

Qiang L, Wang L, Kon N, Zhao W, Lee S, Zhang Y, Rosenbaum M, Zhao Y $\mathrm{Gu}$ W, Farmer SR, et al. 2012 Brown remodeling of white adipose tissue by SirT1-dependent deacetylation of Ppary. Cell 150 620-632. (https://doi.org/10.1016/j.cell.2012.06.027)

Roth J-F, Shikama N, Henzen C, Desbaillets I, Lutz W, Marino S, Wittwer J, Schorle H, Gassmann M \& Eckner R 2003 Differential role of p300 and CBP acetyltransferase during myogenesis: p300 acts upstream of MyoD and Myf5. EMBO Journal 22 5186-5196. (https:// doi.org/10.1093/emboj/cdg473)

Seale P, Conroe HM, Estall J, Kajimura S, Frontini A, Ishibashi J, Cohen P, Cinti S \& Spiegelman BM 2011 Prdm16 determines the thermogenic program of subcutaneous white adipose tissue in mice. Journal of Clinical Investigation 121 96-105. (https://doi.org/10.1172/JCI44271)

Shimomura I, Hammer RE, Richardson JA, Ikemoto S, Bashmakov Y, Goldstein JL \& Brown MS 1998 Insulin resistance and diabetes mellitus in transgenic mice expressing nuclear SREBP-1c in adipose tissue: model for congenital generalized lipodystrophy. Genes and Development 12 3182-3194. (https://doi.org/10.1101/gad.12.20.3182)

Ukropec J, Anunciado RP, Ravussin Y, Hulver MW \& Kozak LP 2006 UCP1-independent thermogenesis in white adipose tissue of cold-acclimated Ucp1-/- mice. Journal of Biological Chemistry 281 31894-31908. (https://doi.org/10.1074/jbc.M606114200)

Vegiopoulos A, Müller-Decker K, Strzoda D, Schmitt I, Chichelnitskiy E, Ostertag A, Berriel Diaz M, Rozman J, Hrabe de Angelis M,
Nüsing RM, et al. 2010 Cyclooxygenase-2 controls energy homeostasis in mice by de novo recruitment of brown adipocytes. Science $\mathbf{3 2 8}$ 1158-1161. (https://doi.org/10.1126/science.1186034)

Vernochet C, Damilano F, Mourier A, Bezy O, Mori MA, Smyth G, Rosenzweig A, Larsson N-G \& Kahn CR 2014 Adipose tissue mitochondrial dysfunction triggers a lipodystrophic syndrome with insulin resistance, hepatosteatosis, and cardiovascular complications. FASEB Journal 28 4408-4419. (https://doi. org/10.1096/fj.14-253971)

Milani D, Manzoni FM, Pezzani L, Ajmone P, Gervasini C, Menni F \& Esposito S 2015 Rubinstein-Taybi syndrome: clinical features, genetic basis, diagnosis, and management. Italian Journal of Pediatrics $\mathbf{4 1} 4$. (https://doi.org/10.1186/s13052-015-0110-1)

Wang F, Mullican SE, DiSpirito JR, Peed LC \& Lazar MA 2013 Lipoatrophy and severe metabolic disturbance in mice with fat-specific deletion of PPARgamma. PNAS 110:18656-18661. (https://doi.org/10.1073/ pnas.1314863110)

Wu J, Boström P, Sparks LM, Ye L, Choi JH, Giang A-H, Khandekar M, Virtanen KA, Nuutila P, Schaart G, et al. 2012 Beige adipocytes are a distinct type of thermogenic fat cell in mouse and human. Cell $\mathbf{1 5 0}$ 366-376. (https://doi.org/10.1016/j.cell.2012.05.016)

Xu C, Bai B, Fan P, Cai Y, Huang B, Law IK, Liu L, Xu A, Tung C, Li X, et al. 2013 Selective overexpression of human SIRT1 in adipose tissue enhances energy homeostasis and prevents the deterioration of insulin sensitivity with ageing in mice. American Journal of Translational Research 5 412-426.

Xu F, Zheng X, Lin B, Liang H, Cai M, Cao H, Ye J \& Weng J 2016 Dietinduced obesity and insulin resistance are associated with brown fat degeneration in SIRT1-deficient mice. Obesity 24 634-642. (https:// doi.org/10.1002/oby.21393)

Yamauchi T, Oike Y, Kamon J, Waki H, Komeda K, Tsuchida A, Date Y, Li M-X, Miki H, Akanuma Y, et al. 2002 Increased insulin sensitivity despite lipodystrophy in Crebbp heterozygous mice. Nature Genetics 30 221-226. (https://doi.org/10.1038/ng829)

Zhang Y, Li R, Meng Y, Li S, Donelan W, Zhao Y, Qi L, Zhang M, Wang X, Cui T, et al. 2014 Irisin stimulates browning of white adipocytes through mitogen-activated protein kinase p38 MAP kinase and ERK MAP kinase signaling. Diabetes 63 514-525. (https://doi.org/10.2337/ db13-1106)

Zhao Y, Zhang Y-D, Zhang Y-Y, Qian S-W, Zhang Z-C, Li S-F, Guo L, Liu Y, Wen B, Lei Q-Y, et al. 2014 p300-dependent acetylation of activating transcription factor 5 enhances $\mathrm{C} / \mathrm{EBP} \beta$ transactivation of $\mathrm{C} / \mathrm{EBP} \alpha$ during 3T3-L1 differentiation. Molecular and Cellular Biology 34 315-324. (https://doi.org/10.1128/MCB.00956-13)

Received in final form 10 October 2018

Accepted 5 November 2018 https://joe.bioscientifica.com

https://doi.org/10.1530/JOE-18-0361 (c) 2019 Society for Endocrinology Published by Bioscientifica Ltd.
Printed in Great Britain 